\title{
Review Article \\ The Clinical Relevance of Force Platform Measures in Multiple Sclerosis: A Review
}

\author{
Luca Prosperini and Carlo Pozzilli \\ Multiple Sclerosis Centre, S. Andrea Hospital, Department of Neurology and Psychiatry, Sapienza University, \\ Viale dell'Università, 30-00185 Rome, Italy \\ Correspondence should be addressed to Luca Prosperini; luca.prosperini@uniromal.it and \\ Carlo Pozzilli; carlo.pozzilli@uniromal.it
}

Received 29 November 2012; Revised 5 February 2013; Accepted 5 February 2013

Academic Editor: Rob Bermel

Copyright ( 2013 L. Prosperini and C. Pozzilli. This is an open access article distributed under the Creative Commons Attribution License, which permits unrestricted use, distribution, and reproduction in any medium, provided the original work is properly cited.

Balance impairment and falls are frequent in patients with multiple sclerosis (PwMS), and they may occur even at the earliest stage of the disease and in minimally impaired patients. The introduction of computer-based force platform measures (i.e., static and dynamic posturography) has provided an objective and sensitive tool to document both deficits and improvements in balance. By using more challenging test conditions, force platform measures can also reveal subtle balance disorders undetectable by common clinical scales. Furthermore, posturographic techniques may also allow to reliably identify PwMS who are at risk of accidental falls. Although force platform measures offer several theoretical advantages, only few studies extensively investigated their role in better managing PwMS. Standardised procedures, as well as clinical relevance of changes detected by static or dynamic posturography, are still lacking. In this review, we summarized studies which investigated balance deficit by means of force platform measures, focusing on their ability in detecting patients at high risk of falls and in estimating rehabilitation-induced changes, highlighting the pros and the cons with respect to clinical scales.

\section{Introduction}

Balance can be defined as the ability to maintain the body's centre of gravity (COG) within the base of support with minimal sway [1]. The control of human balance is a complex task which is assured by uninterrupted flow of afferent signals reaching the central nervous system (CNS) from the muscle, tendon and joint proprioceptors, skin exteroceptors, and vestibular and visual inputs [2]. The deficient integration of these pathways, due to the widespread and variable distribution of CNS damage in patients with multiple sclerosis (PwMS), can affect postural response and the ability to maintain adequate balance [3-5]. Balance impairment is frequently observed in PwMS, and it is among the most disabling symptoms [6]. A wide-base gait with worsening balance when changing direction has been often described in PwMS [7]. Fatigue, muscle weakness, and spasticity further contribute to compromise adequate balance and predispose them to accidental falls [8-11]. Fall tendency may occur early in the course of the disease, even before walking and balance impairment becomes clinically evident [12].

The incidence of accidental falls (i.e., an unexpected contact of any part of the body with the ground) in PwMS has been reported from $30 \%$ to $63 \%$ in a period variable from 1 to 12 months, according to different studies [13-27]. Recently, a large survey on about 195,000 veterans found a 2fold increased risk of injurious falls in PwMS compared with sex/age-matched veterans without MS [28].

Studies investigating demographic and clinical characteristics related to a high risk of accidental falls in PwMS are quite heterogeneous in terms of sample size, setting, and design, and for reporting (retrospectively) or collecting (prospectively) the occurrence of falls [29]. Studies relying on retrospectively collected patient report of falls at the inclusion are prone to recall bias $[16,30]$, although a good correlation $(r=0.82)$ between prospectively and retrospectively collected falls has been demonstrated [16]. In addition, even if prospectively collected, falls resulting in injury are more likely 
to be reported, and cognitive or memory impairment may further decrease the accuracy of their recall $[16,18]$.

From a clinical point of view, reliably discriminating fallers between nonfallers is crucial for the development of a program aimed at fall prevention. Potentially, force platform measures may provide an objective, reliable, and accurate tool for this purpose. Moreover, they may be useful for documenting not only deficits but also improvements of balance skills after specific intervention.

In this review, we aimed to summarize studies investigating the role of force platform measures in MS setting, focusing on (i) differences between PwMS and general population; (ii) ability in detecting PwMS at high risk of falls, highlighting also the differences with clinical scales; (iii) evaluation of rehabilitation-induced changes.

1.1. Clinical Scales to Assess Balance. Clinical tests usually rate balance performance on a set of motor tasks. Scoring is based on the sum of ordinal item scores or stopwatch measurements. Ideally, an evaluation of postural balance should include clinical scales that are practical, sensitive selective, reliable, and valid. Although some clinical scales are easy and relatively quick to use, they are hampered by their variable execution and by the room left for evaluator judgment in the scoring system $[31,32]$. Table 1 summarizes the most commonly used clinical scales to assess balance in PwMS and their main psychometric properties [33-41].

So far, few studies provided data on diagnostic accuracy of clinical scales in detecting PwMS prone to accidental falls. These studies showed conflicting results, probably due to different cutoffs established (see also Table 1). Cattaneo and colleagues [14] showed that clinical balance scales exhibit good specificity (i.e., performance in detecting nonfallers), but low sensitivity (i.e., performance in detecting fallers). Although other authors found differences between fallers and nonfallers in clinical scale scores of balance and even mobility $[20,22,23,25]$, they did not provide data on sensitivity and specificity. Nilsagård and colleagues [16] suggested a combination of patient variables and selected clinical scales to predict the risk of falls but failed to identify the "best candidate" to apply in the daily setting. More recently, it has been suggested that the BESTest was 92\% accurate in identifying fallers and nonfallers among PwMS [35]. Despite this high accuracy, the BESTest is time consuming and requires a lot of tools. The use of a short version (mini-BESTest), having only a 10-minute administration time, could be more useful in clinical practice, but it needs to be validated in PwMS [42]. Lastly, an association between cognitive processing speed and fall frequency has been recently described in PwMS [43]. D'Orio and colleagues [23] also suggested that cognitive impairment, especially impaired verbal memory, predicted an increased risk of recurrent falls.

1.2. Force Platform Measures: Basic Principles. Force platforms are instruments that measure ground reaction forces generated by a body standing on or moving across them, to quantify biomechanical parameters of human balance control. Force platforms are also used for gait analysis.
Posturography is the general term encompassing all the techniques used to quantify postural control in upright stance, in either static or dynamic conditions, by means of a force platform [44]. The term static posturography refers to the characterization of postural sway of the centre of pressure (COP) (i.e., the point of application of the resultant from the vertical force's action) during quiet standing on a fixed support surface (i.e., a relatively unperturbed state). In quiet stance, the COP is estimated as compatible with the centre of gravity at about $97 \%$; this compatibility diminishes in dynamic condition [45]. Variations in the instant positions of the COP during a 30- or 60-second test are used to calculate time-domain measures, including the velocity of the COP on the anteroposterior or mediolateral axes $(\mathrm{mm} / \mathrm{s})$, the sum of the displacements (path) of COP ( $\mathrm{mm}$ ), and the $95 \%$ confidence ellipse area of COP $\left(\mathrm{mm}^{2}\right)$. From abiomechanical standpoint, the displacement of the COP represents a marker of energy expenditure to maintain balance [46]. Usually, a posturographic assessment consists in two test conditions (eyes opened and closed) and, sometimes, in dual-task condition [47]. This paradigm allows an evaluation of cognitive processing required to maintain standing balance, simply by applying a concurrent cognitive task (e.g., aloud or silent backward counting, Stroop test, and paced auditory serial addition test).

Static posturography provides linear, objective, and reliable measurements of static balance [44]. In spite of its reliability and accuracy in PwMS [24, 48], the main limitation of static posturography is a lack of standardisation that precludes the possibility to generalize its application for multicentre purposes. This is due to the fact that different force platform equipment and different test procedures are used in clinical practice. Parameters that should be considered are not well defined (e.g., velocity, path, area, etc.), as well as feet position and test duration [49]. Additionally, static posturography evaluates balance control only in the most simplistic condition, thus not reflecting situations occurring in daily-life activities.

Dynamic posturography involves the use of experimentally induced (external or self-generated) balance perturbation, such as shifting the support surface, using an unstable support surface, moving the visual surround, applying stimuli to upper body parts, and performing voluntary weight shift [50]. By manipulating one or more specific inputs (visual, vestibular, or proprioceptive) for postural control, a dynamic posturography assessment may provide important data on the motor and sensory contribution to balance control [51]. Thereby, impairments in sensory reweighing and integrating afferent inputs can be easily detected. Moreover, these data can be combined into composite scores, such as the equilibrium score or the postural stability index [52]. The main advantage of dynamic posturography is the possibility to obtain information on balance control in a variety of conditions simulating situations encountered in daily-life activities [32]. Unfortunately, it requires a long time of administration and an expensive and bulky equipment. Moreover, subjects cannot maintain balance under the more difficult conditions, especially when they are forced to rely only on vestibular input. A fall frequency as high as $22 \%$ has been reported 
TABLE 1: Commonly used clinical scales to assess balance in patients with multiple sclerosis.

\begin{tabular}{|c|c|c|c|c|c|c|}
\hline Tool & $\begin{array}{l}\text { Authors } \\
\text { Journal }\end{array}$ & Brief description & $\begin{array}{c}\text { Time of } \\
\text { administration }\end{array}$ & $\begin{array}{l}\text { Overall } \\
\text { score }\end{array}$ & $\begin{array}{l}\text { Test-retest } \\
\text { reliability } \\
\text { in PwMS }\end{array}$ & $\begin{array}{l}\text { Accuracy in } \\
\text { predicting fall status } \\
\text { in PwMS }\end{array}$ \\
\hline $\begin{array}{l}\text { Activities- } \\
\text { specific balance } \\
\text { confidence } \\
(\mathrm{ABC})\end{array}$ & $\begin{array}{l}\text { Powell and Myers } \\
\text { [33] } \\
\text { J. Gerontol. A. Biol. } \\
\text { Sci. Med. Sci. } 1995\end{array}$ & $\begin{array}{l}\text { 16-item self-administered } \\
\text { questionnaire rating the perceived } \\
\text { level of confidence in performing } \\
\text { daily living activities }\end{array}$ & 15 minutes & 0 to 100 & $92 \%$ & $\begin{array}{l}\text { SE: } 65 \%, \text { SP: } 77 \% \\
\text { (cutoff: } 40 \text { ) [14] }\end{array}$ \\
\hline $\begin{array}{l}\text { Balance } \\
\text { evaluation } \\
\text { system test } \\
\text { (BESTest) }\end{array}$ & $\begin{array}{l}\text { Horak et al. [34] } \\
\text { Phys. Ther. } 2009\end{array}$ & $\begin{array}{l}\text { 36-item physician-rated scale } \\
\text { evaluating } 6 \text { systems } \\
\text { (biomechanical constraints, stability } \\
\text { limits/verticality, anticipatory } \\
\text { postural adjustments, postural } \\
\text { responses, sensory orientation, and } \\
\text { stability in gait) }\end{array}$ & 30 minutes & 0 to 108 & $88 \%-91 \%^{\mathrm{b}}$ & SE: $86 \%$, SP: $95 \%$ [35] \\
\hline $\begin{array}{l}\text { Berg balance } \\
\text { scale (BBS) }\end{array}$ & $\begin{array}{l}\text { Berg et al. [36] } \\
\text { Can. J. Public Health. } \\
1992\end{array}$ & $\begin{array}{l}\text { 14-item physician-rated scale } \\
\text { exploring the ability to sit, stand, } \\
\text { lean, and turn and postural } \\
\text { transition. }\end{array}$ & 15 minutes & 0 to 56 & $96 \%$ & $\begin{array}{l}\text { SE: } 40 \%, \text { SP: } 90 \% \\
\text { (cutoff: } 44 \text { ) }[14] \\
\text { SE: } 94 \%, \text { SP: } 32 \% \\
\text { (cutoff: } 55 \text { ) }[16] \\
\text { SE: } 32 \%, \text { SP: } 87 \% \\
\text { (cutoff: } 44 \text { ) }[24]\end{array}$ \\
\hline $\begin{array}{l}\text { Dizziness } \\
\text { handicap } \\
\text { inventory } \\
\text { (DHI) }\end{array}$ & $\begin{array}{l}\text { Jacobson and } \\
\text { Newman [37] } \\
\text { Arch. Otolaryngol } \\
\text { Head Neck Surg } 1990\end{array}$ & $\begin{array}{l}\text { Multidimensional } 25 \text {-item } \\
\text { self-administered questionnaire } \\
\text { quantifying the level of disability in } \\
\text { three domains: physical, emotional, } \\
\text { and functional }\end{array}$ & 15 minutes & 0 to $100^{\mathrm{a}}$ & $90 \%$ & $\begin{array}{l}\text { SE: } 50 \%, \text { SP: } 74 \% \\
\text { (cutoff: } 59 \text { ) [14] }\end{array}$ \\
\hline $\begin{array}{l}\text { Dynamic gait } \\
\text { index (DGI) }\end{array}$ & $\begin{array}{l}\text { Whitney et al. [38] } \\
\text { J. Vest. Res. } 2000\end{array}$ & $\begin{array}{l}\text { 8-item physician-rated scale } \\
\text { exploring mobility function and } \\
\text { dynamic balance }\end{array}$ & 10 minutes & 0 to 24 & $85 \%$ & $\begin{array}{l}\text { SE: } 45 \%, \text { SP: } 80 \% \\
\text { (cutoff: } 12 \text { ) [14] }\end{array}$ \\
\hline $\begin{array}{l}\text { Four-square } \\
\text { step test (FSST) }\end{array}$ & $\begin{array}{l}\text { Dite and Temple [39] } \\
\text { Arch. Phys. Med. } \\
\text { Rehabil } 2002\end{array}$ & $\begin{array}{l}\text { Stop-watch measurement of the } \\
\text { duration of rapidly step over low } \\
\text { obstacles in clockwise and } \\
\text { counterclockwise direction }\end{array}$ & $\begin{array}{l}3 \text { minutes or } \\
\text { less }\end{array}$ & N/A & $93 \%-98 \%{ }^{b}$ & $\begin{array}{l}\text { SE: } 60 \%, \text { SP: } 75 \% \\
\text { (cutoff: } 16.9 \text { s) [16] }\end{array}$ \\
\hline $\begin{array}{l}\text { Functional } \\
\text { reach test } \\
(\text { FRT })\end{array}$ & $\begin{array}{l}\text { Duncan et al. [40] } \\
\text { J. Gerontol. } 1990\end{array}$ & $\begin{array}{l}\text { Measurement of the maximum } \\
\text { distance reached forward while } \\
\text { standing in a fixed position. }\end{array}$ & N/A & N/A & $85 \%-95 \%{ }^{\mathrm{b}}$ & - \\
\hline $\begin{array}{l}\text { Timed-up- } \\
\text { and-go test } \\
\text { (TUG) }\end{array}$ & $\begin{array}{l}\text { Podsiadlo and } \\
\text { Richardson [41] } \\
\text { J. Am. Geriatr. Soc. } \\
1991\end{array}$ & $\begin{array}{l}\text { Stop-watch measurement of the } \\
\text { duration of standup from a chair, } \\
\text { walking } 3 \text { meters, turning around, } \\
\text { walking back and siting down. }\end{array}$ & $\begin{array}{c}3 \text { minutes or } \\
\text { less }\end{array}$ & N/A & $98 \%$ & $\begin{array}{l}\text { SE: } 73 \% \text {, SP: } 54 \% \\
\text { (cutoff: } 13.6 \text { s) })^{c}[16]\end{array}$ \\
\hline
\end{tabular}

PwMS: patients with multiple sclerosis; SE: sensitivity; SP: specificity; ${ }^{a}$ the only scale in which the lower the score, lower the level of disability; ${ }^{b}$ as estimated in populations other than MS; ${ }^{c}$ cognitive TUG was used in this study.

while PwMS performed the more challenging conditions of dynamic posturography (i.e., surface moving, eyes opened; surface moving, eyes closed; surface and surround moving, eyes opened) [48].

\section{Methods}

2.1. Data Sources. PubMed was searched for abstracts using the following medical subject heading (MeSH) terms: "multiple sclerosis" AND "posturography" OR "multiple sclerosis" AND "force platform" OR "multiple sclerosis" AND "postural balance." No limitations or time period restrictions were applied and the latest search was undertaken on January 10th 2013, Both prospective and retrospective studies were encompassed. Published conference abstracts,case reports, meta-analyses and reviews, articles not available in English, and studies including also patients affected by neurological conditions other than MS were excluded. Finally, studies where postural sway was measured by means of tools (e.g., accelerometers or gyroscopes) other than force platforms were also excluded. Abstracts of resulting articles were then hand searched in order to select studies which met eligibility criteria. Attempts to identify further articles were done by searching for the references of the studies.

\section{Results}

The search initially yielded a total of 178 articles; out of these, 58 studies conducted on PwMS were selected for this narrative review. After removing duplicates, 35 met the inclusion criteria. In 21 studies, force platform measures were used to detect impairments in balance in PwMS with 


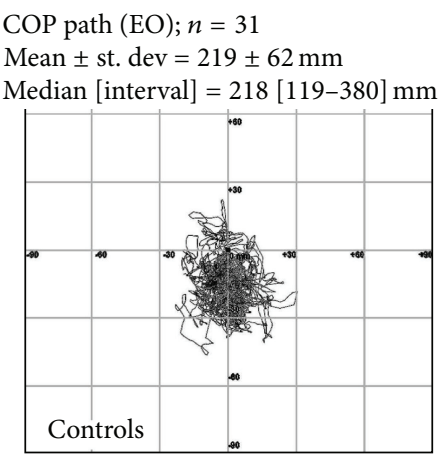

COP path (EC); $n=31$

Mean \pm st. $\operatorname{dev}=325 \pm 121 \mathrm{~mm}$

Median [interval $]=293[141-588] \mathrm{mm}$

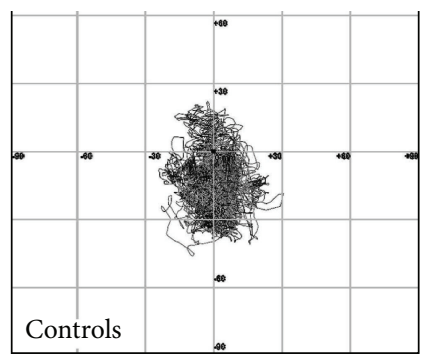

COP path (EO); $n=17$

Mean \pm st. $\mathrm{dev}=352 \pm 136 \mathrm{~mm}$

Median [interval $]=319[197-805] \mathrm{mm}$

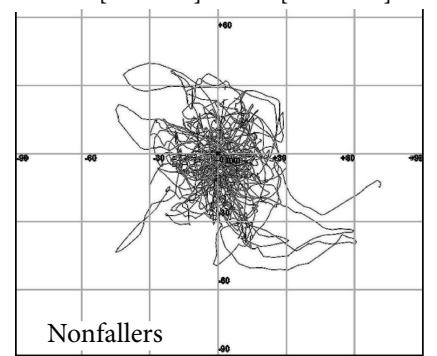

COP path (EC); $n=17$

Mean \pm st. dev $=801 \pm 386 \mathrm{~mm}$

Median [interval $]=693[337-1,392] \mathrm{mm}$

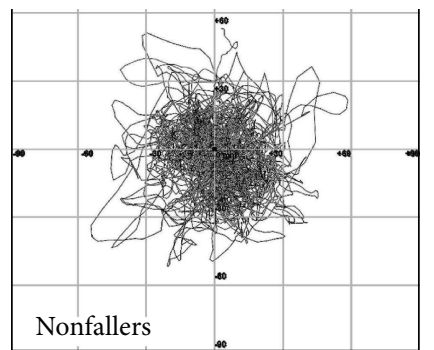

COP path (EO); $n=14$

Mean \pm st. $\operatorname{dev}=585 \pm 357 \mathrm{~mm}$

Median [interval $]=490[298-1,389] \mathrm{mm}$

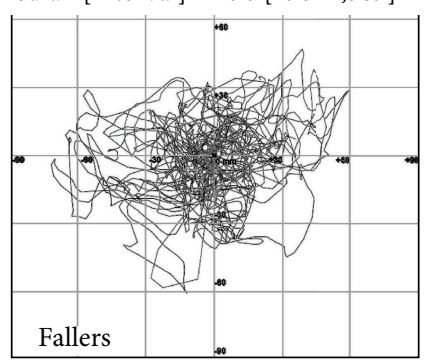

COP path (EC); $n=14$

Mean \pm st. dev $=1,379 \pm 625 \mathrm{~mm}$

Median [interval] $=1,392[520-2,334] \mathrm{mm}$

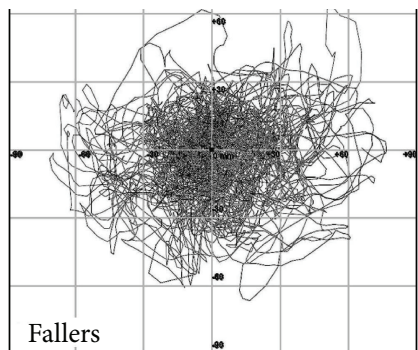

Figure 1: Superimposed displacements of centre of pressure (COP path) on $x$ - $y$-axes with both eyes opened (EO) and closed (EC) (upper and lower rows, resp.) of healthy volunteers (controls, $n=31$ ), patients without a history of falls (nonfallers, $n=17$ ), and those reporting one or more falls in the past 6 months (fallers, $n=14$ ) (modified from [19]).

healthy subjects as control group [48, 53-72]. Five studies investigated the role of force platform measures in detecting fall status of PwMS [17, 19-21, 24]. Finally, 9 studies used force platform measures as outcome measures to determine the effectiveness of a rehabilitative intervention [73-81].

\subsection{Differentiating Balance Control between Patients with} MS and Healthy Subjects. There is a general agreement that PwMS have a postural sway control which is significantly poorer than healthy subjects. PwMS present larger oscillations in the frontal and sagittal planes when compared with healthy controls [17, 19-21, 24, 48, 53-71]. By means of posturography, impaired anticipatory postural adjustments have been also described in PwMS [69].

Furthermore, the sensitivity of force platform measures is such that it can detect balance abnormalities even in minimally impaired PwMS (i.e., scoring as normal in clinical balance test) $[57,63,68]$ or in those presenting a first demyelinating event suggestive of MS [64]. This latter study demonstrated that about $40 \%$ of CIS patients had poor or very poor scores in COP sway rate (i.e., 2-4 or $\geq 4$ standard deviations higher than the mean value of healthy controls, resp.) [64]. Therefore, posturography demonstrates the existence of subclinical balance disorders that cannot be detected by means of clinical assessment, even in PwMS who did not complain about subjective balance impairment [68].

Another common finding of these studies is that postural stability deficit is increased under more challenging conditions, for example, reducing the base of support, suppressing visual or vestibular input, generating external perturbations, and performing a reach and lean task or a cognitive task $[17,54,59,62,64,68]$. It has also been shown that an abnormal performance in quiet standing can be found in $2 / 3$ of PwMS, even when all sensory inputs (visual, vestibular, and proprioceptive) are available; the alteration of a single input can lead to an increase in abnormal findings by up to $82 \%$ [48].

3.2. Predicting the Risk of Future Falls. Up to now, only a few studies investigated the role of force platform measures in predicting the risk of falls in PwMS. Several studies reported fallers as having wider COP sway than nonfallers [19, 20, 24]. Therefore, a gradient of postural disturbance can be hypothesized as follows: PwMS fallers > PwMS nonfallers > healthy subjects (Figure 1) $[19,24]$. However, this hypothesis needs to further confirmations.

Sosnoff and colleagues [20] showed that PwMS classified as fallers exhibited increased COP sway velocity in the mediolateral direction under eyes opened condition, wider overall COP sway area, and greater sway velocity in the anteroposterior and medio-lateral directions under eyes closed condition. Other studies provided similar findings, with fallers' COP moving more and faster in either anteroposterior or mediolateral directions than nonfallers, in both eyes opened and closed eye conditions $[19,24]$.

Kasser and colleagues [17] demonstrated that women with MS who experienced accidental falls were correctly identified by dynamic posturography, which was able to 


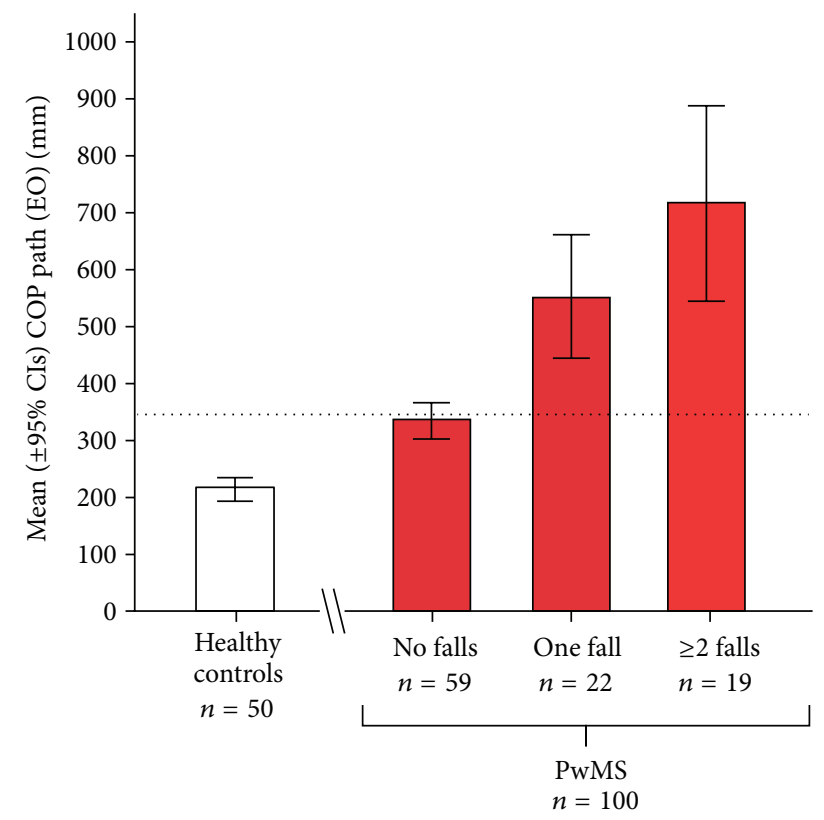

Figure 2: Mean ( $\pm 95 \%$ confidence intervals) values of centre of pressure (COP) path with eyes opened (EO) of healthy volunteers $(n=50)$ and patients with MS $(n=100)$ who were divided according to the number of accidental falls $(0,1, \geq 2)$ prospectively collected over a 3-month follow-up period (modified from [24]).

discriminate patients reporting at least one fall over the past 12 months from those reporting more frequent falls. Impaired forward limit of stability, gait asymmetries, and leg flexorextensor muscle weakness also contributed to detecting recurrent fallers.

Only one recent study supports the notion that the adjunction of posturographic evaluation did not improve the ability to detect PwMS prone to fall [21]. However, as also recognized by authors, there are some limitations to their study: (i) a small sample size $(n=37)$; (ii) the incidence of falls was lower compared to other published papers, probably due to the short observational time-frame considered (2 months); (iii) they did not use traditional force platform measures as outcome, but the derivative virtual time to contact (i.e., the time taken by COP to reach the stability boundaries). Recently, we estimated sensitivity, specificity, and accuracy of static standing balance measures in predicting patients who experienced future falls [24]. We examined 100 consecutive PwMS by means of neurological examination (including the Berg scale) and a static posturography assessment. The patients were instructed to report the occurrence of falls over the next 3 months. Balance measures above the mean plus 2 standard deviations of normal values (as provided by a sample of 50 sex-/age-matched healthy volunteers) were considered as abnormal. From static posturography, the COP path under open eye condition was extrapolated, providing a measure not only highly reliable (95\%) but also more sensitive $(88 \%$ versus $37 \%$ ) and accurate (75\% versus $63 \%)$, but slightly less specific (67\% versus $81 \%$ ) than a common clinical test (such as the Berg scale) in predicting accidental falls. A multivariate logistic regression analysis revealed that there was an $8 \%$ increased risk of being classified as fallers for each $10-\mathrm{mm}$ increase of COP path value, even after adjusting for other demographic and clinical variables. Finally, a "dose effect" of static posturography was also found; that is the wider the COP path, the greater the number of accidental falls prospectively recorded by PwMS (Figure 2) [24].

3.3. Evaluating Rehabilitation-Induced Changes. Force platform measures ensure an objective, reliable, and linear assessment of balance, avoiding the risk of ceiling effect [32]. Force platform measures demonstrated a high sensitivity in detecting rehabilitation-induced changes and sometimes provided more rewarding results than clinical scales [7477, 79-81]. Concurrent improvements in postural sway measures, clinical, and/or patient-reported outcomes were always described [74-77, 79-81]. Only two studies did not show any improvement of postural sway measures of PwMS after home-based resistance exercises [73] and balance-based torso weighting [78].

One recent study aimed at investigating the effectiveness of a 12-week home-based balance training using a commercial videogame platform showed also a slight increase in the proportion of nonfallers when compared with the 3month period prior to study enrolment [81]. However, this latter study was not designed (and not powered to perform a post hoc analysis) to estimate a relationship between force platform measure changes and clinically relevant outcomes.

Unfortunately, there are still no data on the clinimetric property [82] of responsiveness of force platform measures, assessed by minimally important change (MIC) over time (i.e., the change that is relevant for the patient) and smallest real change (SRC) (i.e., the change on a measurement instrument required to overcome the measurement error). Therefore, future research efforts are warranted to establish MIC and SRC for force platform measures.

\section{Conclusions}

Balance impairment and falls are frequent in PwMS, and they may occur even at the earliest stage of the disease. Reliably identifying subjects who are at risk of accidental falls is a clinical challenge. Asking about the presence of prior falls is unreliable because patients often neglect their falls. Clinical balance scales are hampered by their variable execution and subjective scoring system, thus providing conflicting results about their ability to detect patients prone to falls.

By contrast, within few minutes, computer-based force platform measures of standing and dynamic balance can provide useful information regarding the risk of future falls, as well as intervention-induced changes. Moreover, computerised postural sway measures have been reported as correlated with disability and functional scales [24, 35, 65, 83]. Table 2 summarizes pros and cons pros of force platform measures, contrasted with those of clinical measures.

Although relevant, the differences in postural control between PwMS and healthy subjects cannot definitively elucidate the neuropathological mechanisms leading to balance 
TABLE 2: Summary of pros and cons of force platform measures and clinical scales.

\begin{tabular}{|c|c|c|}
\hline & $\begin{array}{l}\text { Force platform } \\
\text { measures }\end{array}$ & $\begin{array}{l}\text { Clinical } \\
\text { scales }\end{array}$ \\
\hline \multicolumn{3}{|l|}{ Equipment } \\
\hline Expensive & $\mathrm{Y}$ & $\mathrm{N}$ \\
\hline Cumbersome & $\mathrm{Y}$ & $\mathrm{N}$ \\
\hline Training of staff required & $\mathrm{Y}$ & $\mathrm{Y} / \mathrm{N}^{\mathrm{a}}$ \\
\hline \multicolumn{3}{|l|}{ Data collection } \\
\hline Easy and fast to administer & $\mathrm{Y} / \mathrm{N}^{\mathrm{b}}$ & $\mathrm{Y} / \mathrm{N}^{\mathrm{b}}$ \\
\hline $\begin{array}{l}\text { Affected by emotional status or } \\
\text { external factors }\end{array}$ & $\mathrm{Y}$ & $\mathrm{Y}$ \\
\hline Invasive for patients & $\mathrm{N}$ & $\mathrm{Y} / \mathrm{N}^{\mathrm{c}}$ \\
\hline \multicolumn{3}{|l|}{ Statistical consideration } \\
\hline Linear values & $\mathrm{Y}$ & $\mathrm{N}$ \\
\hline Objective measurements & $\mathrm{Y}$ & $\mathrm{N}$ \\
\hline Ceiling effect & $\mathrm{N}$ & $\mathrm{Y}$ \\
\hline Reliability & $\mathrm{Y}$ & $\mathrm{Y}$ \\
\hline \multicolumn{3}{|l|}{ Clinical utility } \\
\hline Detection of subclinical impairment & $\mathrm{Y}$ & $\mathrm{N}$ \\
\hline $\begin{array}{l}\text { Identification of underlying causes of } \\
\text { imbalance }\end{array}$ & $\mathrm{Y} / \mathrm{N}^{\mathrm{d}}$ & $\mathrm{Y} / \mathrm{N}^{\mathrm{d}}$ \\
\hline Prediction of falls & $\mathrm{Y}$ & $\mathrm{Y}$ \\
\hline Ability in detecting improvements & $\mathrm{Y}$ & $\mathrm{Y}$ \\
\hline
\end{tabular}

impairments in MS. Given the widespread and variable distribution of CNS damage, it is generally thought that postural control impairment in PwMS has multifactorial causes that differ from one person to the next $[4,17]$. Studies investigating the structure-function relationship by means of force platform measures do not provide comparable results. Jackson and colleagues [55] suggested that postural balance deficit in PwMS resulted from impaired central integration of visual, vestibular, and somatosensory input. Slowed afferent proprioceptive conduction along demyelinated dorsal columns of spinal cord has been proposed as an important cause of impaired postural control [84, 85]. Another hypothesis proposes the damage of cerebellar connections (i.e., cerebellar peduncles) as the primary contributor to the balance impairment [19] or, more extensively, the focal and diffuse involvement of the cerebellum, its connections, and other associative regions [5].

4.1. Future Recommendations. Posturographic systems have become more affordable and potentially useful for both clinical practice and research purposes. Nevertheless, they still represent a significant cost (especially dynamic posturography equipment) need a dedicated space and trained staff to run the tests. This is not always feasible in a clinical practice setting. A possible solution to overcome the main drawbacks of laboratory-grade force platforms could be the implementation of software to interface a commercial Nintendo balance board with a common personal computer [86]. Similarly to laboratory-grade force platform, the balance board contains force sensors which detect subject's COP and weight shifts. This commercial device-that has been recently included in the neurorehabilitation process of PwMS [79-81] - is low expensive, portable, and user friendly. In conclusions, further efforts are warranted to establish (i) which parameters of balance (velocity, path, area, etc.) should be evaluated; (ii) normative values for the force platform measures; (iii) how to standardize the posturographic assessment for multicentre study purposes; (iv) the ecological validity of this tool.

\section{References}

[1] L. M. Nashner, "Sensory, neuromuscular, and biomechanical contributions to human balance," in Proceedings From the American Physical Therapy Association Forum, pp. 5-12, Nashville, Tenn, USA, 1982.

[2] R. Fitzpatrick and D. I. McCloskey, "Proprioceptive, visual and vestibular thresholds for the perception of sway during standing in humans," Journal of Physiology, vol. 478, part 1, pp. 173-186, 1994.

[3] W. G. Herrera, "Vestibular and other balance disorders in multiple sclerosis. Differential diagnosis of disequilibrium and topognostic localization," Neurologic Clinics, vol. 8, no. 2, pp. 407-420, 1990.

[4] M. H. Cameron and S. Lord, "Postural control in multiple sclerosis: implications for fall prevention," Current Neurology and Neuroscience Reports, vol. 10, no. 5, pp. 407-412, 2010.

[5] L. Prosperini, E. Sbardella, E. Raz et al., "White and grey matter damage associated with balance deficit as detected by static posturography in multiple sclerosis," Radiology, 2013.

[6] C. Martyn, McAlpine's Mult Sclerosis, Churchill Livingstone, Oxford, UK, 4th edition, 2005.

[7] L. Tesio, "Ataxia and imbalance in multiple sclerosis," in Multiple Sclerosis: Recovery of Function and Neurorehabilitation, Cambridge University Press, Cambridge, UK, 2010.

[8] D. Frzovic, M. E. Morris, and L. Vowels, "Clinical tests of standing balance: performance of persons with multiple sclerosis," Archives of Physical Medicine and Rehabilitation, vol. 81, no. 2, pp. 215-221, 2000.

[9] H. Stolze, S. Klebe, C. Zechlin, C. Baecker, L. Friege, and G. Deuschl, "Falls in frequent neurological diseases: prevalence, risk factors and aetiology," Journal of Neurology, vol. 251, pp. 7984, 2004.

[10] J. J. Sosnoff, E. Gappmaier, A. Frame, and R. W. Motl, "Influence of spasticity on mobility and balance in persons with multiple sclerosis," Journal of Neurologic Physical Therapy, vol. 35, no. 3, pp. 129-132, 2011.

[11] R. E. A. Van Emmerik, J. G. Remelius, M. B. Johnson, L. H. Chung, and J. A. Kent-Braun, "Postural control in women with multiple sclerosis: effects of task, vision and symptomatic fatigue," Gait \& Posture, vol. 32, no. 4, pp. 608-614, 2010.

[12] S. M. Moen, E. G. Celius, L. Nordsletten, and T. Holmøy, "Fractures and falls in patients with newly diagnosed clinically isolated syndrome and multiple sclerosis," Acta Neurologica Scandinavica, vol. 191, pp. 79-82, 2011.

[13] D. Cattaneo, C. De Nuzzo, T. Fascia, M. Macalli, I. Pisoni, and R. Cardini, "Risks of falls in subjects with multiple sclerosis," 
Archives of Physical Medicine and Rehabilitation, vol. 83, no. 6, pp. 864-867, 2002.

[14] D. Cattaneo, A. Regola, and M. Meotti, "Validity of six balance disorders scales in persons with multiple sclerosis," Disability and Rehabilitation, vol. 28, no. 12, pp. 789-795, 2006.

[15] M. L. Finlayson, E. W. Peterson, and C. C. Cho, "Risk factors for falling among people aged 45 to 90 years with multiple sclerosis," Archives of Physical Medicine and Rehabilitation, vol. 87, no. 9, pp. 1274-1279, 2006.

[16] Y. Nilsagård, C. Lundholm, E. Denison, and L. G. Gunnarsson, "Predicting accidental falls in people with multiple sclerosisA Longitudinal Study," Clinical Rehabilitation, vol. 23, no. 3, pp. 259-269, 2009.

[17] S. L. Kasser, J. V. Jacobs, J. T. Foley, B. J. Cardinal, and G. F. Maddalozzo, "A prospective evaluation of balance, gait, and strength to predict falling in women with multiple sclerosis," Archives of Physical Medicine and Rehabilitation, vol. 92, pp. 1840-1846, 2011.

[18] P. N. Matsuda, A. Shumway-Cook, A. M. Bamer, S. L. Johnson, D. Amtmann, and G. H. Kraft, "Falls in multiple sclerosis," $P M$ \& $R$, vol. 3, pp. 624-632, 2011.

[19] L. Prosperini, A. Kouleridou, N. Petsas et al., "The relationship between infratentorial lesions, balance deficit and accidental falls in multiple sclerosis," Journal of the Neurological Sciences, vol. 304, no. 1-2, pp. 55-60, 2011.

[20] J. J. Sosnoff, M. J. Socie, M. K. Boes et al., "Mobility, balance and falls in persons with multiple sclerosis," PLoS One, vol. 6, Article ID e28021, 2011.

[21] D. Cattaneo, M. Ferrarin, J. Jonsdottir, A. Montesano, and M. Bove, "The virtual time to contact in the evaluation of balance disorders and prediction of falls in people with multiple sclerosis," Disability and Rehabilitation, vol. 34, pp. 470-477, 2012.

[22] S. Coote, S. Hogan, and S. Franklin, "Falls in people with multiple sclerosis who used a walking aid: prevalence, factors, and effect of strength and balance interventions," Archives of Physical Medicine and Rehabilitation, vol. 94, no. 4, pp. 616-621, 2013.

[23] V. L. D’Orio, F. W. Foley, F. Armentano, M. A. Picone, S. Kim, and R. Holtzer, "Cognitive and motor functioning in patients with multiple sclerosis: neuropsychological predictors of walking speed and falls," Journal of the Neurological Sciences, vol. 316, pp. 42-46, 2012.

[24] L. Prosperini, D. Fortuna, C. Giannì, L. Leonardi, and C. Pozzilli, "The diagnostic accuracy of static posturography in predicting accidental falls in people with multiple sclerosis," Neurorehabilitation and Neural Repair, vol. 27, pp. 45-52, 2013.

[25] M. J. Socie, B. M. Sandroff, J. H. Pula, E. T. Hsiao-Wecksler, R. W. Motl, and J. J. Sosnoff, "Footfall placement variability and falls in multiple sclerosis," Annals of Biomedical Engineering, 2012.

[26] J. J. Sosnoff, B. M. Sandroff, J. H. Pula, S. M. Morrison, and R. W. Motl, "Falls and physical activity in persons with multiple sclerosis," Multiple Sclerosis International, vol. 2012, Article ID 315620, 5 pages, 2012.

[27] Y. Nilsagård, A. Carling, and A. Forsberg, "Activities-specific balance confidence in people with multiple sclerosis," Multiple Sclerosis International, vol. 2012, Article ID 613925, 8 pages, 2012.

[28] M. H. Cameron, A. J. Poel, J. K. Haselkorn, A. Linke, and D. Bourdette, "Falls requiring medical attention among veterans with multiple sclerosis: A Cohort Study," Journal of Rehabilitation Research and Development, vol. 48, no. 1, pp. 13-20, 2011.
[29] H. J. Gunn, P. Newell, B. Haas, J. F. Marsden, and J. A. Freeman, "Identification of risk factors for falls in multiple sclerosis: a systematic review and meta-analysis," Physical Therapy, vol. 93, no. 4, pp. 504-513, 2013.

[30] S. R. Cummings, M. C. Nevitt, and S. Kidd, "Forgetting falls. The limited accuracy of recall of falls in the elderly," Journal of the American Geriatrics Society, vol. 36, no. 7, pp. 613-616, 1988.

[31] M. Mancini and F. B. Horak, "The relevance of clinical balance assessment tools to differentiate balance deficits," European Journal of Physical and Rehabilitation Medicine, vol. 46, no. 2, pp. 239-248, 2010.

[32] J. E. Visser, M. G. Carpenter, H. van der Kooij, and B. R. Bloem, "The clinical utility of posturography," Clinical Neurophysiology, vol. 119, no. 11, pp. 2424-2436, 2008.

[33] L. E. Powell and A. M. Myers, "The Activities-specific Balance Confidence (ABC) scale," The Journals of Gerontology A, vol. 50, no. 1, pp. M28-M34, 1995.

[34] F. B. Horak, D. M. Wrisley, and J. Frank, "The Balance Evaluation Systems Test (BESTest) to differentiate balance deficits," Physical Therapy, vol. 89, no. 5, pp. 484-498, 2009.

[35] J. V. Jacobs and S. L. Kasser, "Balance impairment in people with multiple sclerosis: preliminary evidence for the Balance Evaluation Systems Test," Gait \& Posture, vol. 36, pp. 414-418, 2012.

[36] K. O. Berg, S. L. Wood-Dauphinee, J. I. Williams, and B. Maki, "Measuring balance in the elderly: validation of an instrument," Canadian Journal of Public Health, vol. 2, pp. S7-S11, 1992.

[37] G. P. Jacobson and C. W. Newman, "The development of the Dizziness Handicap Inventory," Archives of Otolaryngology, vol. 116, no. 4, pp. 424-427, 1990.

[38] S. L. Whitney, M. T. Hudak, and G. F. Marchetti, "The dynamic gait index relates to self-reported fall history in individuals with vestibular dysfunction," Journal of Veterinary Research, vol. 10, no. 2, pp. 99-105, 2000.

[39] W. Dite and V. A. Temple, "A clinical test of stepping and change of direction to identify multiple falling older adults," Archives of Physical Medicine and Rehabilitation, vol. 83, no. 11, pp. 15661571, 2002.

[40] P. W. Duncan, D. K. Weiner, J. Chandler, and S. Studenski, "Functional reach: a new clinical measure of balance," Journal of Gerontology, vol. 45, no. 6, pp. M192-M197, 1990.

[41] D. Podsiadlo and S. Richardson, "The timed "Up \& Go": a test of basic functional mobility for frail elderly persons," Journal of the American Geriatrics Society, vol. 39, no. 2, pp. 142-148, 1991.

[42] F. Franchignoni, F. Horak, M. Godi, A. Nardone, and A. Giordano, "Using psychometric techniques to improve the balance evaluation systems test: the mini-bestest," Journal of Rehabilitation Medicine, vol. 42, no. 4, pp. 323-331, 2010.

[43] J. J. Sosnoff, S. Balantrapu, L. A. Pilutti, B. M. Sandroff, S. Morrison, and R. W. Motl, "Cognitive processing speed is related to fall frequency in older adults with multiple sclerosis," Archives of Physical Medicine and Rehabilitation, 2013.

[44] J. M. R. Furman, R. W. Baloh, K. Barin et al., "Assessment: posturography. Report of the Therapeutics and Technology Assessment Subcommittee of the American Academy of Neurology," Neurology, vol. 43, pp. 1261-1264, 1993.

[45] D. A. Winter, A. E. Patla, and J. S. Frank, "Assessment of balance control in humans," Medical Progress through Technology, vol. 16, no. 1-2, pp. 31-51, 1990.

[46] H. Houdijk, R. Fickert, J. van Velzen, and C. van Bennekom, "The energy cost for balance control during upright standing," Gait \& Posture, vol. 30, no. 2, pp. 150-154, 2009. 
[47] M. Woollacott and A. Shumway-Cook, "Attention and the control of posture and gait: a review of an emerging area of research," Gait \& Posture, vol. 16, no. 1, pp. 1-14, 2002.

[48] D. Cattaneo and J. Jonsdottir, "Sensory impairments in quiet standing in subjects with multiple sclerosis," Multiple Sclerosis Journal, vol. 15, no. 1, p. 59, 2009.

[49] K. Le Clair and C. Riach, "Postural stability measures: what to measure and for how long," Clinical Biomechanics, vol. 11, no. 3, pp. 176-178, 1996.

[50] B. R. Bloem, J. E. Visser, and J. H. Allum, "Posturography," in Movement Disorders: Handbook of Clinical Neurophysiology, M. Hallett, Ed., pp. 295-336, Elsevier, 2003.

[51] L. M. Nashner, C. L. Shupert, F. B. Horak, and F. O. Black, "Organization of posture controls: an analysis of sensory and mechanical constraints," Progress in Brain Research, vol. 80, pp. 411-418, 1989.

[52] H. Chaudhry, T. Findley, K. S. Quigley et al., "Postural stability index is a more valid measure of stability than equilibrium score," Journal of Rehabilitation Research and Development, vol. 42, no. 4, pp. 547-555, 2005.

[53] M. L. Daley and R. L. Swank, "Quantitative posturography: use in multiple sclerosis," IEEE Transactions on Biomedical Engineering, vol. 28, no. 9, pp. 668-671, 1981.

[54] M. L. Daley and R. L. Swank, "Changes in postural control and vision induced by multiple sclerosis," Agressologie, vol. 24, no. 7, pp. 327-329, 1983.

[55] R. T. Jackson, C. M. Epstein, and W. R. De l'Aune, "Abnormalities in posturography and estimations of visual vertical and horizontal in multiple sclerosis," American Journal of Otology, vol. 16, no. 1, pp. 88-93, 1995.

[56] S. R. Nelson, R. P. Di Fabio, and J. H. Anderson, "Vestibular and sensory interaction deficits assessed by dynamic platform posturography in patients with multiple sclerosis," Annals of Otology, Rhinology and Laryngology, vol. 104, no. 1, pp. 62-68, 1995.

[57] G. M. Karst, D. M. Venema, T. G. Roehrs, and A. E. Tyler, "Center of pressure measures during standing tasks in minimally impaired persons with multiple sclerosis," Journal of Neurologic Physical Therapy, vol. 29, no. 4, pp. 170-180, 2005.

[58] P. Rougier, M. Faucher, S. Cantalloube, D. Lamotte, M. Vinti, and P. Thoumie, "How proprioceptive impairments affect quiet standing in patients with multiple sclerosis," Somatosensory and Motor Research, vol. 24, no. 1-2, pp. 41-51, 2007.

[59] C. Fjeldstad, G. Pardo, C. Frederiksen, D. Bemben, and M. Bemben, "Assessment of postural balance in multiple sclerosis," International Journal of MS Care, vol. 11, pp. 1-5, 2009.

[60] A. Porosińska, K. Pierzchała, M. Mentel, and J. Karpe, "Evaluation of postural balance control in patients with multiple sclerosis-effect of different sensory conditions and arithmetic task execution. A Pilot Study," Neurologia i Neurochirurgia Polska, vol. 44, no. 1, pp. 35-42, 2010.

[61] J. J. Sosnoff, S. Shin, and R. W. Motl, "Multiple sclerosis and postural control: the role of spasticity," Archives of Physical Medicine and Rehabilitation, vol. 91, no. 1, pp. 93-99, 2010.

[62] R. E. A. Van Emmerik, J. G. Remelius, M. B. Johnson, L. H. Chung, and J. A. Kent-Braun, "Postural control in women with multiple sclerosis: effects of task, vision and symptomatic fatigue," Gait \& Posture, vol. 32, no. 4, pp. 608-614, 2010.

[63] C. Fjeldstad, G. Pardo, D. Bemben, and M. Bemben, "Decreased postural balance in multiple sclerosis patients with low disability," International Journal of Rehabilitation Research, vol. 34, no. 1, pp. 53-58, 2011.
[64] A. Kalron, Z. Dvir, and A. Achiron, "Effect of a cognitive task on postural control in patients with a clinically isolated syndrome suggestive of multiple sclerosis," European Journal of Physical and Rehabilitation Medicine, vol. 47, pp. 579-586, 2011.

[65] N. Kessler, M. M. Ganança, C. F. Ganança et al., "Balance Rehabilitation Unit (BRU) posturography in relapsing-remitting multiple sclerosis," Arquivos De Neuro-Psiquiatria, vol. 69, pp. 485-490, 2011.

[66] H. Negahban, R. Mofateh, A. A. Arastoo et al., "The effects of cognitive loading on balance control in patients with multiple sclerosis," Gait \& Posture, vol. 34, pp. 479-484, 2011.

[67] A. Yahia, S. Ghroubi, C. Mhiri, and M. H. Elleuch, "Relationship between muscular strength, gait and postural parameters in multiple sclerosis," Annals of Physical and Rehabilitation Medicine, vol. 54, pp. 144-155, 2011.

[68] M. H. Fanchamps, H. Gensicke, J. Kuhle et al., "Screening for balance disorders in mildly affected multiple sclerosis patients," Journal of Neurology, vol. 259, pp. 1413-1419, 2012.

[69] V. Krishnan, N. Kanekar, and A. S. Aruin, "Anticipatory postural adjustments in individuals with multiple sclerosis," Neuroscience Letters, vol. 506, pp. 256-260, 2012.

[70] M. K. Boes, J. J. Sosnoff, M. J. Socie, B. M. Sandroff, J. H. Pula, and R. W. Motl, "Postural control in multiple sclerosis: effects of disability status and dual task," Journal of the Neurological Sciences, vol. 315, pp. 44-48, 2012.

[71] J. R. Hebert and J. R. Corboy, "The association between multiple sclerosis-related fatigue and balance as a function of central sensory integration," Gait \& Posture, 2012.

[72] J. M. Huisinga, J. M. Yentes, M. L. Filipi, and N. Stergiou, "Postural control strategy during standing is altered in patients with multiple sclerosis," Neuroscience Letters, vol. 524, pp. 124128, 2012.

[73] L. S. DeBolt and J. A. McCubbin, "The effects of home-based resistance exercise on balance, power, and mobility in adults with multiple sclerosis," Archives of Physical Medicine and Rehabilitation, vol. 85, no. 2, pp. 290-297, 2004.

[74] V. Hatzitaki, A. Koudouni, and A. Orologas, "Learning of a novel visuo-postural co-ordination task in adults with multiple sclerosis," Journal of Rehabilitation Medicine, vol. 38, no. 5, pp. 295-301, 2006.

[75] O. Schuhfried, C. Mittermaier, T. Jovanovic, K. Pieber, and T. Paternostro-Sluga, "Effects of whole-body vibration in patients with multiple sclerosis: A Pilot Study," Clinical Rehabilitation, vol. 19, no. 8, pp. 834-842, 2005.

[76] B. Missaoui and P. Thoumie, "How far do patients with sensory ataxia benefit from so-called "proprioceptive rehabilitation"?" Neurophysiologie Clinique, vol. 39, no. 4-5, pp. 229-233, 2009.

[77] G. L. Widener, D. D. Allen, and C. Gibson-Horn, "Balancebased torso-weighting may enhance balance in persons with multiple sclerosis: preliminary evidence," Archives of Physical Medicine and Rehabilitation, vol. 90, no. 4, pp. 602-609, 2009.

[78] G. L. Widener, D. D. Allen, and C. Gibson-Horn, "Randomized clinical trial of balance-based torso weighting for improving upright mobility in people with multiple sclerosis," Neurorehabilitation and Neural Repair, vol. 23, no. 8, pp. 784-791, 2009.

[79] I. Guidi, T. Giovannelli, and M. Paci, "Effects of Wii exercises on balance in people with multiple sclerosis," Multiple Sclerosis Journal, 2012.

[80] G. Brichetto, P. Spallarossa, M. L. de Carvalho, and M. A. Battaglia, "The effect of Nintendo Wii on balance in people with multiple sclerosis: A Pilot Randomized Control Study," Multiple Sclerosis Journal, 2013. 
[81] L. Prosperini, D. Fortuna, C. Gianni, L. Leonardi, M. R. Marchetti, and C. Pozzilli, "Home-based balance training using the Wii Balance Board: a randomized, cross-over Pilot Study in multiple sclerosis," Neurorehabilitation and Neural Repair, 2013.

[82] European Multiple Sclerosis Platform, Recommendations on Rehabilitation Services for Persons with Multiple Sclerosis in Europe, Brussels, Belgium, 2012.

[83] H. Cao, L. Peyrodie, S. Boudet et al., "Expanded Disability Status Scale (EDSS) estimation in multiple sclerosis from posturographic data," Gait \& Posture, vol. 37, no. 2, pp. 242-245, 2013.

[84] M. H. Cameron, F. B. Horak, R. R. Herndon, and D. Bourdette, "Imbalance in multiple sclerosis: a result of slowed spinal somatosensory conduction," Somatosensory \& Motor Research, vol. 25, no. 2, pp. 113-122, 2008.

[85] K. M. Zackowski, S. A. Smith, D. S. Reich et al., "Sensorimotor dysfunction in multiple sclerosis and column-specific magnetization transfer-imaging abnormalities in the spinal cord," Brain, vol. 132, no. 5, pp. 1200-1209, 2009.

[86] R. A. Clark, A. L. Bryant, Y. Pua, P. McCrory, K. Bennell, and M. Hunt, "Validity and reliability of the Nintendo Wii Balance Board for assessment of standing balance," Gait \& Posture, vol. 31, no. 3, pp. 307-310, 2010. 


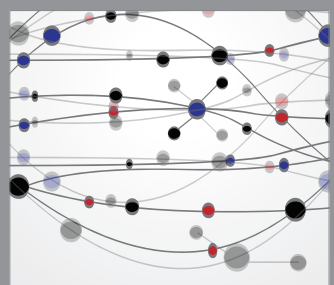

The Scientific World Journal
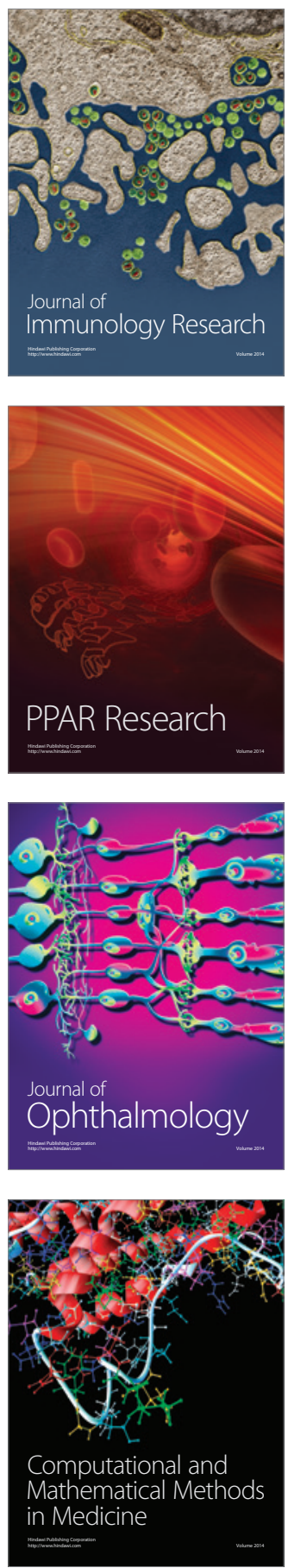

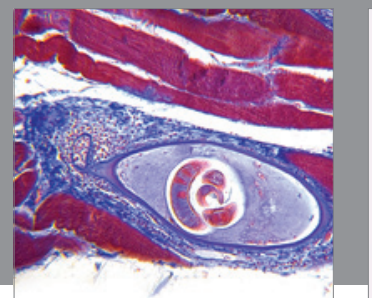

Gastroenterology

Research and Practice
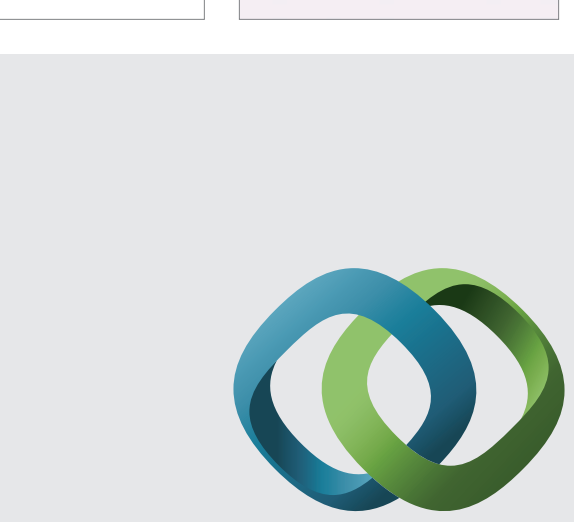

\section{Hindawi}

Submit your manuscripts at

http://www.hindawi.com
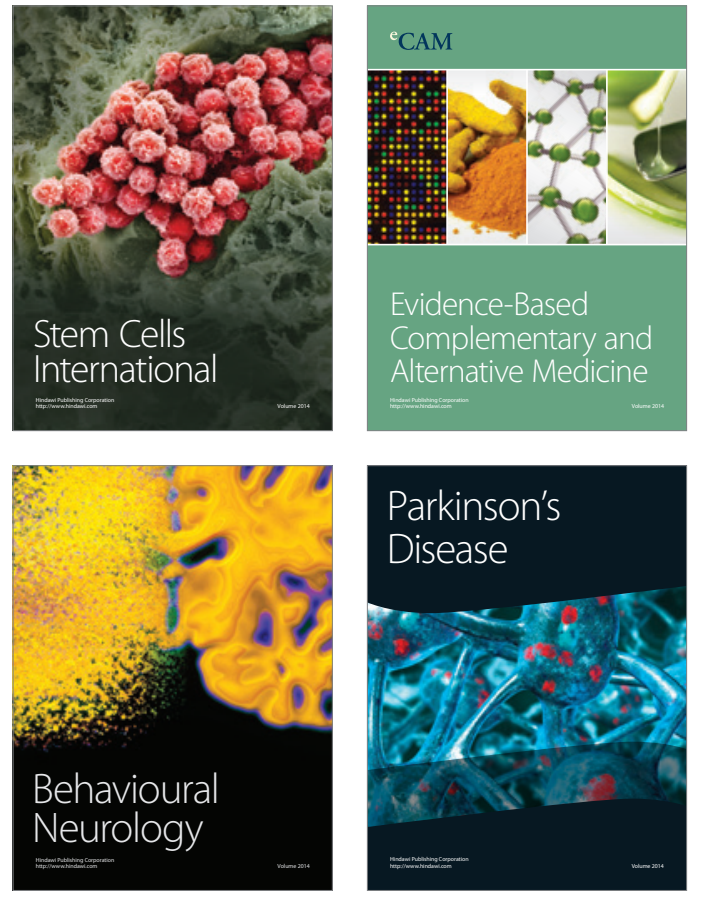
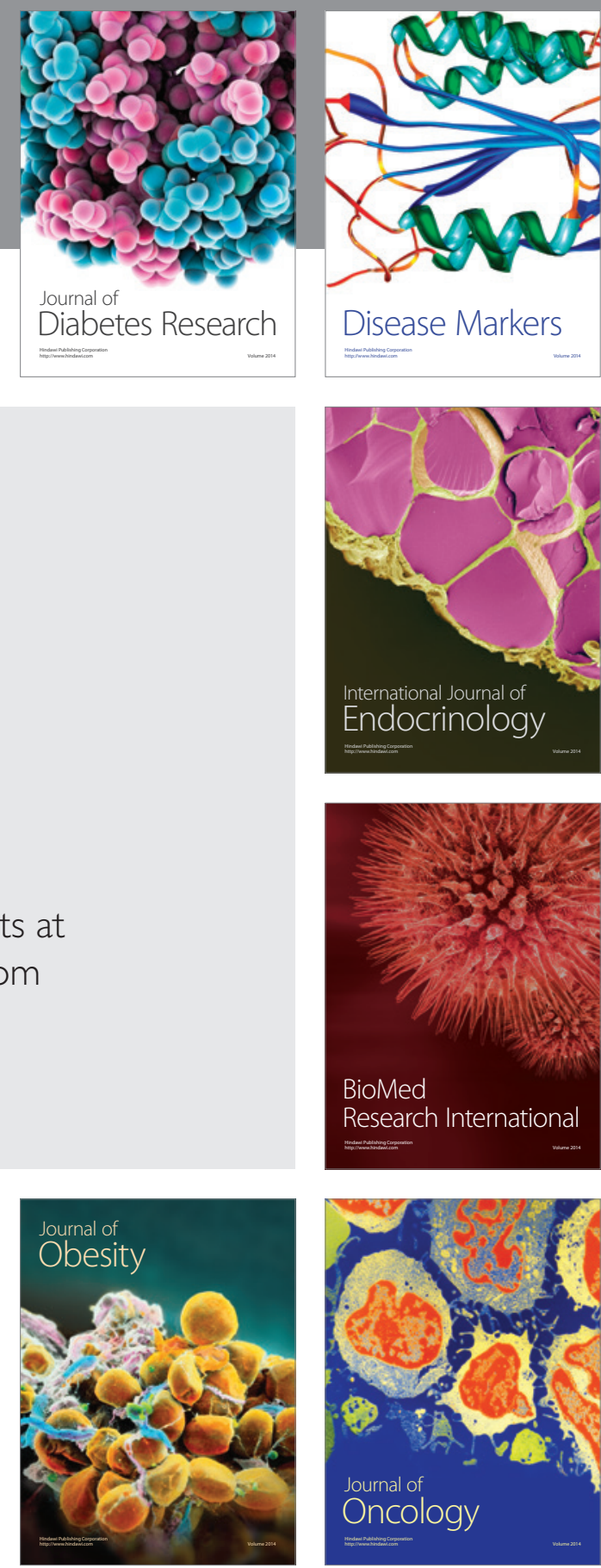

Disease Markers
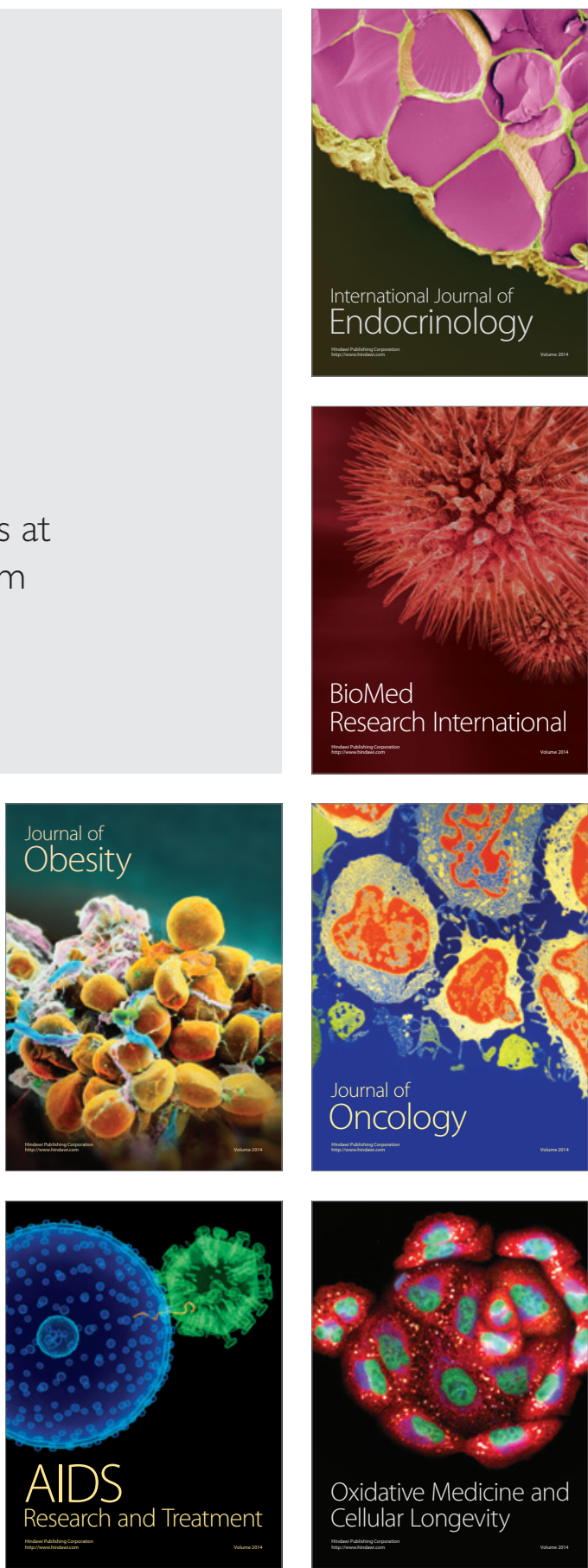